\title{
Characteristics of Phosphorus Adsorption and Release in Different Types of Sediments
}

\author{
${ }^{1}$ Pengqiang Yang ${ }^{*}{ }^{2}$ Huanghe, ${ }^{3}$ Rujun Gao \\ ${ }^{1}$ College of Chemistry and Environmental Engineering, Yangtze University, Hubei 434023, PR China \\ ${ }^{2,3}$ Changjiang University, Jingzhou City, Hubei Province, China
}

\begin{abstract}
Taking different types of sediments as the research object, this research studied the adsorption and release characteristics of phosphorus under different conditions of different temperatures, coexisting heavy metal ion system, organic matter content and sediment particle size. Through used correlation analysis and principal component analysis, it discussed the influence of various factors on the adsorption and release of phosphorus in sediments. The results show that the adsorption of phosphorus by five different types of sediments from different sources reached saturation equilibrium in about 10 hours, and the increasing rates of $0{ }^{\circ} \mathrm{C}, 15^{\circ} \mathrm{C}$ and $30{ }^{\circ} \mathrm{C}$ are $17.5 \% \sim 23.7 \%$ and $18.2 \% \sim 38.3 \%$, respectively. The addition of coexisting heavy metal ion solution accelerated the adsorption of phosphorus in the sediment and reduced the total amount of phosphorus adsorption, that is, heavy metal ions inhibited the adsorption of phosphorus in the sediment; the presence of organic matter in the sediment would reduce its adsorption of phosphorus , Taihu farm and wetland sampling points have the largest sediment organic matter content. Compared with the other three points, the adsorption of phosphorus of these two points accounted for $20.6 \%$ and $22.1 \%$; the adsorption and release of phosphorus by sediment increased with the decrease of particle size. The maximum release rate was $5.216 \mathrm{mg} / \mathrm{kg}-1 \bullet \mathrm{h}-1$. The result of principal component analysis shows that the order of influence on the adsorption and release of phosphorus by sediments is temperature> disturbance> organic matter content> heavy metal ion influence> particle size of sediments.
\end{abstract}

Keywords: Sediment, Phosphorus, Adsorption, Desorption

In ecosystems such as land and lakes, phosphorus is an indispensable nutrient element. However, the frequent eutrophication events in recent years have aroused great concern about phosphorus. Sediment is the main existence site of phosphorus and an important "sink" and "source" of phosphorus. Suspended particles in water will eventually deposit at the bottom due to disturbance and sedimentation, and these sediments have a strong affinity for dissolved phosphorus. At the same time, the migration and transformation of phosphorus will also change with the migration of sediment and the change of the phosphorus content in the sediment.Therefore, the phosphorus in these solid phases controls the phosphorus content in overlying water under different environmental conditions. Phosphorus adsorption and precipitation is considered to be an important mechanism for phosphorus removal in solid phase in aquatic ecosystems. Sakadevan and Bavor's ${ }^{[1]}$ research on wetland soil shows that the adsorption of wetland ecosystems can remove phosphorus in sewage. The main functions are physical and chemical adsorption, microorganism uptake and plant absorption. The adsorption and release of phosphorus in water are closely related to the disturbance amplitude and temperature of water, the content and valence state of $\mathrm{pH}$ heavy metal, phosphorus content, phosphorus form and organic matter content in the sediment, sediment particle size and other factors. Studies ${ }^{[2]}$ have shown that co-existing anions will affect the adsorption of phosphate by niobium hydroxide, and the co-existing anions will form adsorption competitiveness, which will reduce the amount of phosphate adsorption. The researches of Hu Hongqing et al ${ }^{[3]}$ show that organic acids in natural soil are mixtures of multiple components. Its effects with single organic acid and phosphorus are often different. However, the competition studies between single organic acid and phosphorus have provided methods and interaction mechanisms for the study of organic acids in mixed systems. Through pot experiment, Xu Xiangying et al ${ }^{[4]}$ showed that under low concentration of cadmium, phosphorus application could reduce the content of 
cadmium in plant roots; adding phosphorus under high concentration of cadmium helps to form stable cadmium minerals in the soil, while excessive phosphate could induce $\mathrm{Cd}^{2+}$ precipitation.

The above researches show that the adsorption and release of phosphorus has a complex interaction with the existing solid phase and liquid phase. In sediments, phosphate and heavy metal ions may compete for adsorption and chelate with organic matter, activated aluminum, iron, calcium and other oxides. However, there are few studies on the influence of various factors on the adsorption and release of phosphorus. In this study, sediments from different sources were collected, and a certain concentration of phosphorus solution was artificially prepared to conduct experiments on the adsorption and release of phosphorus by sediments. By changing the temperature, the coexistence system of heavy metal ions, the time and degree of adsorption disturbance and other factors, the experimental exploration of isothermal adsorption and adsorption kinetics was carried out. And through principal component analysis method for data processing and interpretation, the degree of influence of various factors in the process of sediment adsorption and release of phosphorus have been further explained, providing a theoretical basis for the treatment and prevention of regional phosphorus eutrophication.

\section{Materials and methods}

\subsection{An overview of the research area}

The sediment samples used in the experiment were collected in Jingzhou City, Hubei Province (longitude: $112^{\circ} 14^{\prime} 20.39^{\prime \prime}$, latitude: $30^{\circ} 20^{\prime} 06.00$ "), as shown in Figure 1 below.With a subtropical monsoon climate, Jingzhou has a mild climate, with an average annual temperature of $16.5^{\circ} \mathrm{C}$, an average temperature of 3.7 ${ }^{\circ} \mathrm{C}$ in January, an average temperature of $27.7^{\circ} \mathrm{C}$ in July, and abundant rainfall.In October 2018, ten sampling points (as shown in Figure 1) with clay minerals and organic matter as main components in Jingzhou City were used to collect sediments of $20 \mathrm{~cm}$ in rivers and lakes with plastic column samplers (length: $100 \mathrm{~cm}$, diameter: $5 \mathrm{~cm}$ ) Samples are stored in plastic bags. The deposited deposits were retrieved and then placed in a plastic bucket to be naturally dried. The deposits were crushed with a wooden hammer and transferred to a wooden mortar for grinding, and then sieved in a plastic sieve. After sieving, the samples were placed in a refrigerator at $-4^{\circ} \mathrm{C}$ and stored for future use.

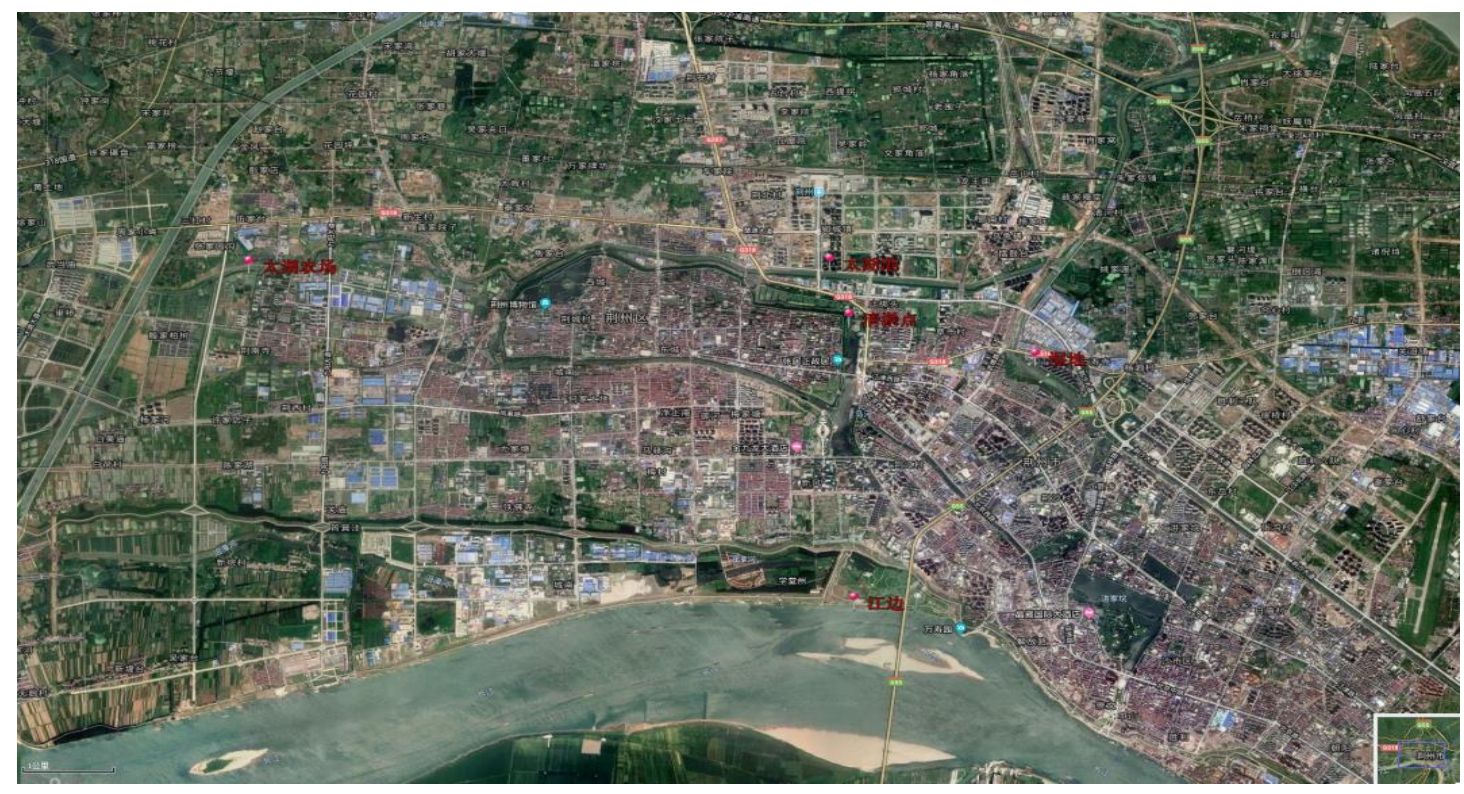

Fig.1 different types of sediment sampling points from different sources

\subsection{Experimental part}

\subsection{The determination of the basic properties of samples}

\subsubsection{The nature of sediment}

In this study, total organic carbon (TOC), cation exchange capacity (CEC) and particle size analysis were performed on the sediment.

TOC measurement: A beaker with a capacity of $50 \mathrm{~mL}$ was washed with hydrochloric acid with $\mathrm{pH}=4$, treated with a carbonation-free treatment and to a constant amount in an oven at $105^{\circ} \mathrm{C} .2 .000 \mathrm{mg}$ of ground 
200 mesh sieve sediment samples were weighed into the beaker; $5 \mathrm{~mL}$ of $\mathrm{pH}=4 \mathrm{HCl}$ solution was added, and when the soil solution was free of bubbles, the beaker was placed on a $105^{\circ} \mathrm{C}$ electric heating plate until the solution is nearly dry. The beaker was then moved to an oven at $105^{\circ} \mathrm{C}$, dried to constant weight, and weighed. The quality of the treated soil was calculated to obtain the ratio of the soil before and after treatment, and the soil was ground again, and the treated sample was stored in a desiccator for analysis. The sample processing setup was repeated twice ${ }^{[5] .}$

The determination of cation exchange amount: According to the method specified in the national standard "Determination of Forest Cationic Soil Exchange Capacity" LY / T 1243-1999, the method of ammonium acetate centrifugal exchange was used. For the method and operation steps, see LY / T 1243-1999.

Particle size analysis: S3500 laser particle size analyzer was used for on-board testing.

\subsubsection{The separation method of phosphorus morphology}

The SMT separation method developed under the framework of the European Standard Test Committee was adopted to divide the TP into inorganic phosphorus (IP), organic phosphorus (OP), exchangeable phosphorus (Ex-P), iron-aluminum combined phosphorus $(\mathrm{NaOH}-\mathrm{P})$ and calcium-bound phosphorus (HCl$\mathrm{P})$ for analysis. Phosphorus was measured by molybdenum antimony resistance spectrophotometry. Each sample was measured twice in parallel, and the data was expressed as the average result of the measurement.

\subsection{The phosphorus adsorption characteristics of sediments}

The adsorption temperature is set as the representative temperature of the four seasons in Jingzhou. $15^{\circ} \mathrm{C}$ in spring and autumn, $35{ }^{\circ} \mathrm{C}$ in summer, and $0{ }^{\circ} \mathrm{C}$ in winter.

\subsubsection{Isothermal adsorption experiment}

The sediments of 10 sampling points were taken as the experimental objects of phosphorus isotherm adsorption. $0.5 \mathrm{~g}$ of sediment was weighed through a 100 mesh sieve and placed in a series of $50 \mathrm{~mL}$ centrifuge tubes. $20 \mathrm{~mL}$ of $\mathrm{KH} 2 \mathrm{PO} 4$ with concentrations of $0,0.1,0.5,1,2,5$, and $10 \mathrm{mg} \cdot \mathrm{L}^{-1}$ were accurately added as the initial concentration. An appropriate amount of chloroform with a concentration of $0.1 \%$ was added dropwise to inhibit bacterial activity. The centrifuge tubes were shaken with a lid plug and shaken at 0,15 and $35^{\circ} \mathrm{C}$ for $24 \mathrm{~h}$, the shock speed was $250 \mathrm{r} \cdot \mathrm{min}^{-1}$. Immediately after sampling, the samples were centrifuged at $5000 \mathrm{r} \cdot \mathrm{min}^{-1}$ for $10 \mathrm{~min}$, and the supernatant was taken through a $0.45 \mu \mathrm{m}$ filter membrane to determine the concentration of soluble reactive phosphorus. The phosphorus absorbed in the sediment was the difference between the initial concentration and the equilibrium concentration. For each temperature and each sampling point, three parallel samples were made, and the average value was used for analysis.

\subsubsection{Kinetic adsorption experiment}

The sediments at 10 sampling points were used as phosphorus kinetic adsorption experiment objects. $0.5 \mathrm{~g}$ of 100 -mesh sieve dry mud was weighed and put into a $50 \mathrm{~mL}$ centrifuge tube. $20 \mathrm{~mL}$ of $\mathrm{KH}_{2} \mathrm{PO}_{4}$ with a concentration of $0.5 \mathrm{mg} \cdot \mathrm{L}-1$ (initial phosphorus concentration) were accurately added. 2 drops of $0.1 \%$ chloroform were added. The centrifuge tube was shaken with a lid stopper and shaken at a constant temperature at $250 \mathrm{r} \cdot \mathrm{min}^{-1}$. The sampling time interval was $0,0.5,1,2,4,6,8,12,24,48,60$ and $72 \mathrm{~h}$, and $0 \mathrm{~h}$ was the starting time of the shaker. After each sampling, the samples were immediately centrifuged at $5000 \mathrm{r} \cdot \mathrm{min}^{-1}$ for $10 \mathrm{~min}$, and the supernatant was taken through a $0.45 \mu \mathrm{m}$ filter membrane to determine the concentration of soluble reactive phosphorus. The phosphorus absorbed in the sediment was the difference between the initial phosphorus concentration and the equilibrium concentration. Three parallel samples were made for each experiment, and the average value was taken during analysis.

\subsubsection{Phosphorus release experiment in sediment}

In the kinetic release experiment, $0.5 \mathrm{~g}$ of 100 -mesh sieve dry mud was weighed and put into a $50 \mathrm{~mL}$ centrifuge tube, $20 \mathrm{~mL}$ ultrapure water (initial phosphorus concentration) was added accurately, and the sampling interval was $0,0.5,1,2,4.8,12 \mathrm{~h}, 24 \mathrm{~h}$ and $48 \mathrm{~h}$, other experimental processes were consistent with kinetic adsorption.

\subsubsection{Langmuir and Freundlich adsorption model}

(1) Langmuir adsorption model: 


$$
\frac{C_{e}}{Q_{e}}=\frac{C_{e}}{Q_{\max }}+\frac{1}{K_{L} Q_{\max }}
$$

In the formula: $C_{\mathrm{e}}$ is the concentration of phosphorus in the balanced solution $\left(\mathrm{mg} \cdot \mathrm{L}^{-10}\right) . \mathrm{Q}_{\mathrm{e}}$ is the amount of phosphorus ( $\mathrm{mg} / \mathrm{kg}$ ) adsorbed by the sediment when reaching the balance, $\mathrm{Q}_{\max }$ is the maximum amount of phosphorus adsorbed, the amount of which can explain the amount of adsorption relative to adjacent phosphorus adsorption points to a certain extent; $\mathrm{K}_{\mathrm{L}}$ is the adsorption equilibrium constant, the positive and negative values and the size of which reflect the energy level of the adsorbent for phosphorus adsorption to a certain extent, relating to factors such as temperature, adsorbent and adsorbate. The larger the $\mathrm{K}_{\mathrm{L}}$ value is , the better the adsorption performance for phosphorus is.

(2) Freundlich adsorption model:

$$
\lg Q_{e}=\lg K_{L}+\frac{1}{n} \lg C_{e}
$$

In the formula: $\mathrm{Q}_{\mathrm{e}}$ is the adsorption amount of phosphorus by the sediment $(\mathrm{mg} / \mathrm{kg}$ ) when the equilibrium has been reached, and $\mathrm{K}_{\mathrm{L}}$ can be regarded as the adsorption amount per unit concentration. Generally, $\mathrm{K}_{\mathrm{L}}$ decreases as temperature goes up. Ce is the concentration of phosphorus $\left(\mathrm{mg} \cdot \mathrm{L}^{-1}\right)$ in the equilibrium solution. The value of $1 / \mathrm{n}$ is generally between 0 and 1 , which indicates the strength of the effects of concentration on the adsorption capacity. The smaller $1 / \mathrm{n}$, the better the adsorption performance. When $1 /$ $\mathrm{n}$ is $0.1 \sim 0.5$, it is easy to adsorb; when $1 / \mathrm{n}>2$, it is difficult to adsorb [6].

In order to facilitate comparison, the experimental data was directly fitted with linear equations:

$$
\mathrm{Q}=\mathrm{KC}+\mathrm{a}
$$

In the formula: $\mathrm{K}$ is the adsorption equilibrium coefficient, $\mathrm{c}$ is the adsorption equilibrium mass concentration $\mathrm{mg} \cdot \mathrm{g}^{-1}$, and a is a constant;

\subsubsection{Phosphorus absorption-holding equilibrium concentration $\mathrm{EPC}_{\mathbf{0}}$}

The buffer capacity of phosphorus refers to the ability of the soil to inhibit changes in the concentration of phosphorus in the dissolved phase. The initial concentration of phosphorus at a low concentration can be used for linear fitting and the equation is:

$$
\mathrm{Q}=\mathrm{KC}_{0} \text {-NAP }
$$

In the formula, $\mathrm{Q}$ is the amount of phosphorus adsorbed by the sediment $(\mathrm{mg} / \mathrm{kg}), \mathrm{C}_{0}$ is the initial phosphorus concentration of the solution ( $\mathrm{mg} / \mathrm{L}$ ), and NAP is the background phosphorus absorption by the sediment $(\mathrm{mg} / \mathrm{kg})^{[7]}$.

In the process of sediment adsorption and desorption of phosphorus, the concentration of phosphorus in the liquid phase when reaching the dynamic equilibrium of adsorption and desorption. The intercept between the linear fitting equation and the $\mathrm{x}$-axis is $\mathrm{EPC}_{0}(\mathrm{mg} / \mathrm{L}) . \mathrm{EPC}_{0}$ can be used to characterize the ability of phosphorus to enter the liquid phase from the solid phase and the magnitude of the risk ${ }^{[8]}$.

\subsubsection{The experiment of the influence of heavy metal content}

There is a more complicated relationship between heavy metals and phosphorus in sediments. Studies have shown that ${ }^{[9 \sim 12]}$, there is an antagonistic effect between phosphate ions and copper in the soil, and the longterm application of phosphate fertilizer will lead to the loss of heavy metal copper in the soil; Fan Ting et al. found that the migration, transformation and enrichment of heavy metals in the soil affected the normal growth of soil crops. There are specific and non-specific points in the sediment that compete for the adsorption of heavy metal ions and phosphate ions, and at the same time, they chelate with the organic matter, iron, magnesium, calcium and other substances contained in the sediment to inhibit the adsorption of phosphorus by the sediment. This paper explores the law of adsorption-desorption of phosphorus in coexisting solutions of different heavy metal ions, and analyzes the possible adsorption-desorption behavior through adsorption kinetic curves, and uses principal component analysis to process the data to obtain the degree to which heavy metal ions affected the amount of phosphorus adsorbed in the sediment was obtained. 
$\mathrm{CrCl}_{3}, \mathrm{FeCl}_{3}, \mathrm{CuCl}_{2}$ and $\mathrm{CdCl}_{2}$ solutions of the same molar mass were prepared, mixed and added to $20 \mathrm{ml}$ $0.5 \mathrm{mg} / \mathrm{L}$ phosphate solution containing $0.500 \mathrm{~g}$ sediment, which was then put into a constant temperature shaker, and shaked at $150 \mathrm{rmp}$ for $24 \mathrm{~h}$.After the shaking was over, the solution was passed through a 0.45 $\mu \mathrm{m}$ filter membrane, and the supernatant was taken to dissolve and set the volume to measure the phosphorus content.

\section{Data processing}

Principal component analysis (or principal quantitative analysis) and softwares such as SPSS18.0 and Origin were used to perform correlation analysis and result processing on the data, and calculate the adsorption parameters at the same time.

\section{Experimental results and discussion}

\subsection{The basic physical and chemical properties of sediments from different sources}

The physical and chemical properties of the collected sediment samples were analyzed, and the analysis results are shown in Table 1 . The difference coefficient of organic matter at each sampling point was $27.54 \%$, and the difference coefficient was relatively small, therein the organic carbon content of the dredging point was the highest with a content of $2.52 \%$, the possible reason of which was that the sample collection at the dredging point was Jingzhou moat. Due to the large number of residents and commercial activities around the moat, the surface runoff and domestic water in the residential area were more likely to be discharged into the moat, therefore it contained more organic matter. The amount of cation exchange is one of the main factors affecting soil cation exchange and soil fertility. The difference coefficient of cation exchange capacity was $7.7 \%$, and the difference was small. For the sediments, Taihu Port had the highest total phosphorus content and the dredging point the lowest. Except for Taihu Farm, the sediments at the five samplingpoints were mainly powder particles. The possible reason is that Taihu Farm is an artificial planting area. The sediments in this area have good permeability, strong water, fertilizer retention capacity, and small stacking gaps ${ }^{[13]}$.

Table 1: Basic properties of the sediment

\begin{tabular}{|c|c|c|c|c|c|c|}
\hline Sampling point & $\begin{array}{l}\text { TOC } \\
\%\end{array}$ & $\begin{array}{l}\text { CEC } \\
\mathrm{cmol} / \mathrm{kg}\end{array}$ & $\begin{array}{l}\mathrm{TP} \\
\mathrm{mg} / \mathrm{kg}\end{array}$ & $\begin{array}{l}\text { Clay particles }(<2 \mu \mathrm{m}) \\
\%\end{array}$ & $\begin{array}{l}\text { Powder }(2 \sim 63 \mu m) \\
\%\end{array}$ & $\begin{array}{l}\text { Sand }(63 \sim 200 \mu m) \\
\%\end{array}$ \\
\hline Dredging point & 2.52 & 16.3 & 374.6 & 10.8 & 77.8 & 11.4 \\
\hline Wetland & 1.93 & 17.2 & 481.3 & 13.3 & 73.4 & 13.3 \\
\hline Riverside & 1.04 & 13.55 & 553.6 & 11.7 & 71.6 & 16.7 \\
\hline Taihu Farm & 1.35 & 15.53 & 376.63 & 75.8 & 21 & 3.2 \\
\hline Taihu Port & 1.81 & 15.86 & 654.8 & 11.2 & 72.3 & 16.5 \\
\hline
\end{tabular}

\subsection{The release of sediment phosphorus}

In this study, the sediments of five different sources in the moat of Jingzhou and surrounding wetlands, lakes, and rivers were taken as the research objects. The amount of phosphorus released by each sediment in the saturated state was experimentally explored and analyzed (Table 2). As can be seen from Table 2, sediments from different sources exhibited different capabilities for phosphorus release. Within $0 \sim 0.5 \mathrm{~h}$, the release rate of phosphorus was the fastest, and the release rate ranged from $60 \%$ to $70 \%$. As the release progresses, the release rate of phosphorus decreased from $0.5 \mathrm{~h}$ to $8 \mathrm{~h}$, ranging from $30 \%$ to $45 \%$. By 24 hours, the equilibrium point of release was basically reached. This conclusion is consistent with related research results (Li Beigang, 2010) ${ }^{[14]}$. In addition, sediments of different particle sizes show different capabilities for phosphorus release. The sediment's release rate and release amount of phosphorus in the wetland and Taihu farm are large, and the content of powder and sand in the particles is less than that of the dredging point, riverside and Taihu port. The possible reason is that coarse particles with larger particle sizes have a smaller specific surface area, less plasticity and cohesiveness, and a slower phosphorus release rate. 
In addition, the release rate and amount of phosphorus may be related to the phosphorus content of different forms of sediment.

Table 2: P release rates at different times

\begin{tabular}{|l|l|l|l|l|l|l|l|l|l|}
\hline \multirow{2}{*}{ Sampling point } & \multicolumn{7}{|l|}{ Phosphorus release rate at different times $\left(\mathbf{m g} / \mathbf{k g}^{-\mathbf{1}} \mathbf{h}^{-\mathbf{1}}\right)$} \\
\cline { 2 - 12 } & $\mathbf{0 h}$ & $\mathbf{0 . 5 h}$ & $\mathbf{1 h}$ & $\mathbf{2 h}$ & $\mathbf{4 h}$ & $\mathbf{8 h}$ & $\mathbf{1 2 h}$ & $\mathbf{2 4 h}$ & $\mathbf{4 8 h}$ \\
\hline Taihu Port & 4.742 & 1.846 & 1.033 & 0.564 & 0.316 & 0.184 & 0.121 & 0.096 & 0.089 \\
\hline Dredging point & 4.691 & 1.673 & 1.026 & 0.631 & 0.373 & 0.223 & 0.142 & 0.099 & 0.087 \\
\hline Taihu Farm & 4.965 & 1.921 & 1.169 & 0.676 & 0.421 & 0.251 & 0.185 & 0.161 & 0.159 \\
\hline Wetland & 5.216 & 1.568 & 1.005 & 0.568 & 0.335 & 0.172 & 0.118 & 0.101 & 0.089 \\
\hline Riverside & 4.237 & 1.178 & 0.718 & 0.364 & 0.192 & 0.112 & 0.084 & 0.064 & 0.061 \\
\hline
\end{tabular}

3.3 The kinetic curves of phosphorus adsorption by different types of sediments

The curve in Figure 2 shows the adsorption kinetics of phosphorus in five different types of sediments in 8 different time periods. The amount of phosphorus adsorbed by the sediments in different time periods are different. However, the variation of the overall adsorption amount tends to be the same. The fast adsorption rate is mostly concentrated in $0 \sim 1 \mathrm{~h}$. With the progress of the adsorption process, the adsorption points on the adsorbent are gradually saturated with adsorption. The adsorption is relatively stable around 10h, and the adsorption basically reaches the adsorption equilibrium around $24 \mathrm{~h}$.

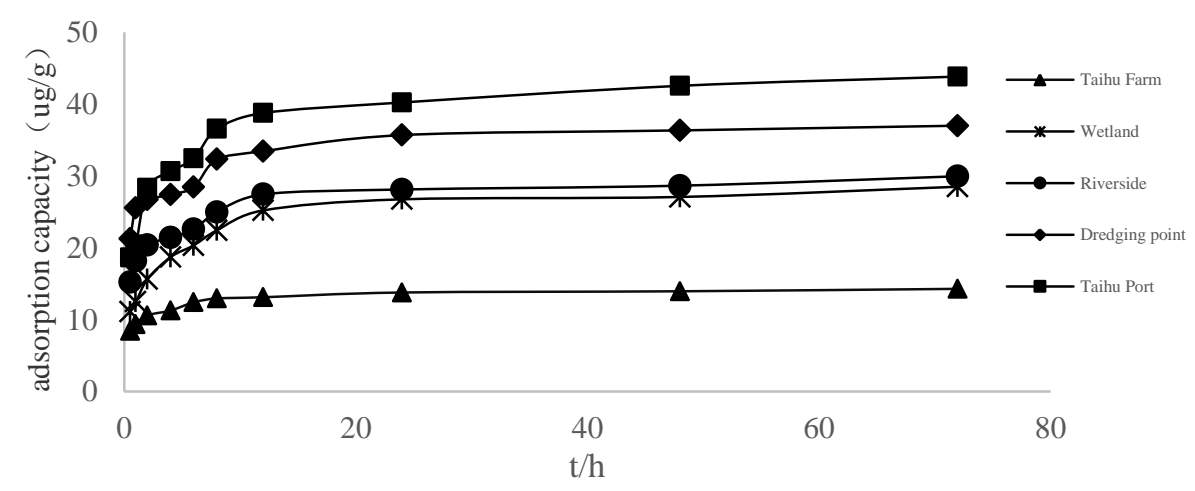

Figure. 2 the phosphorus adsorption kinetic curves of different types of sediments

\subsection{Isothermal adsorption and model}

According to the formula (1) (4), the data was analyzed with the adsorption model, and the results are shown in the following table.

Table.3: Linear-fitting parameters of isothermic adsorption of $P$ by the sediments from different types of sediment

\begin{tabular}{|c|c|c|c|c|c|c|c|c|c|c|c|}
\hline \multirow[b]{2}{*}{$\begin{array}{l}\text { Sampling } \\
\text { point }\end{array}$} & \multirow[b]{2}{*}{$\begin{array}{l}\text { Temperatu } \\
\text { re / }{ }^{\circ} \mathrm{C}\end{array}$} & \multicolumn{6}{|c|}{$\begin{array}{l}\text { Langmuir } \\
\text { model }\end{array}$} & \multicolumn{4}{|c|}{ Linear equation } \\
\hline & & $\begin{array}{l}\text { Qmax } \\
/ \text { mg } \cdot \mathbf{g}^{-1}\end{array}$ & $\begin{array}{l}\mathbf{K} \\
/ \mathbf{L} \cdot \mathbf{k g}^{-1}\end{array}$ & $\mathbf{R}^{2}$ & n & $\begin{array}{l}\mathbf{K} \\
/ \mathbf{L} \cdot \mathbf{k g}^{-1}\end{array}$ & $\mathbf{R}^{2}$ & $\begin{array}{l}\mathrm{K} \\
/ \mathbf{L} \cdot \mathrm{kg}^{-}\end{array}$ & $\begin{array}{l}\text { NAP } \\
/ \mathbf{m g} / \mathbf{k} \\
\mathbf{g}^{-1}\end{array}$ & $\begin{array}{l}\mathrm{EPC}_{0} \\
\mathrm{mg} / \mathrm{L}^{-1}\end{array}$ & $\mathbf{R}^{2}$ \\
\hline Taihu Port & 15 & 0.89 & 0.06 & 0.986 & 0.95 & 0.22 & 0.985 & 21.7 & 4.47 & 0.21 & 0.994 \\
\hline
\end{tabular}




\begin{tabular}{|c|c|c|c|c|c|c|c|c|c|c|}
\hline $\begin{array}{l}\text { Dredging } \\
\text { point }\end{array}$ & 0.82 & 0.07 & 0.981 & 0.91 & 0.22 & 0.917 & 19.4 & 3.63 & 0.19 & 0.991 \\
\hline Riverside & 0.74 & 0.09 & 0.98 & 0.8 & 0.11 & 0.973 & 18.3 & 3.11 & 0.17 & 0.995 \\
\hline Wetland & 0.99 & 0.05 & 0.982 & 1.33 & 0.32 & 0.983 & 26.9 & 2.08 & 0.08 & 0.996 \\
\hline $\begin{array}{l}\text { Taihu } \\
\text { Farm }\end{array}$ & 0.61 & 0.08 & 0.975 & 0.88 & 0.13 & 0.973 & 15.4 & 1.93 & 0.13 & 0.991 \\
\hline
\end{tabular}

The above equations (1) and (2) were used to fit the isothermal adsorption results correspondingly. Table 3 shows the fitting results.It can be seen from this that the maximum adsorption capacities of phosphorus in sediments at different sampling points were different. The Langmuir adsorption model results show that the maximum adsorption of phosphorus on wetland sediments is the highest, followed by Taihu Port and dredging point; the maximum adsorption of phosphorus on sediments of Taihu Farm is the lowest.The fitting results of Langmuir equation and Freundlich equation to the isotherm adsorption isotherm of sediments from different sources reached extremely significant levels, $\mathrm{R}^{2}$ was $0.975 \sim 0.986$ and $0.917 \sim 0.985$ respectively. Therefore, other parameters of sediment adsorption can be calculated according to the two equations. The maximum adsorption amount of sediment Qmax can reflect the amount of phosphorus adsorption points. From the data of the Langmuir adsorption model in the table, it can be seen that the Qm of the wetland sediment is the largest. The $\mathrm{Q}_{\mathrm{m}} \mathrm{s}$ of Taihu Port, riverside and the dredging point are relatively higher. The sediments of Taihu Farm have the lowest The sediments of Taihu Farm have the lowest Qm. This shows that the wetland sediments have the largest phosphorus adsorption points, while the Taihu Farm sediments have the least phosphorus adsorption points and the lowest adsorption capacity; The possible reason is that the land of Taihu Farm is mostly agricultural land, and the adsorption of phosphorus on farmland soil is relatively weak. Therefore, the phosphorus fertilizer applied is likely to be lost with irrigation or runoff. Taihu Farm may be used as a phosphorus source to import phosphorus into the surrounding environment. According to the Linear equation, the soil phosphorus buffering capacity is expressed by the slope $\mathrm{K}\left(\mathrm{L}^{\mathrm{kg}} \mathrm{kg}^{-}\right.$ ${ }^{1}$ ). Wetland sampling points have the largest buffer capacity for phosphorus, followed by Taihu Port, dredging points and riverside. Taihu Farm has the weakest buffer capacity for phosphorus adsorption and release, which may have a lot to do with the source and use of sediment at the sampling points. Compared with Taihu Farm, the amount of man-made fertilization and intervention received by the wetlands, Taihu Port, dredging sites and riverside sediments was less, and phosphorus input was less.

\subsection{The relationship between the phosphorus form and the adsorption capacity in the sediment}

In the SMT phosphorus separation method, the total phosphorus is the sum of inorganic phosphorus and organic phosphorus. Inorganic phosphorus (IP) is the sum of iron-aluminum-bound phosphorus and calcium-bound phosphorus, and each form of phosphorus can be mutually checked ${ }^{[15]}$. The relationship between the different forms of phosphorus, organic matter, cation exchange capacity and so on in the sediment and the maximum adsorption capacity Qmax is shown in Table 4 below. It can be seen from Table 4 that the sediments showed a significant positive correlation with Ex-P $(p<0.01)$ and a significant positive correlation with TP $(\mathrm{P}<0.05)$. The possible reason is that the exchangeable phosphorus is greatly affected by sediments and water, and water is more likely to migrate in water and surface sediments. The sediments in Taihu Port sampling point have high TP, IP and iron-aluminum combined phosphorus content, respectively $654.8 \mathrm{mg} / \mathrm{kg}$, 530mg / kg and 304.38mg / kg, which is because the Taihu Port watershed passes through many residential areas, farm areas, industrial areas, etc., and phosphorus-containing sewage will be discharged along the way. The sediments in the rivers of Taihu Port have absorbed part of the phosphorus in the water phase, and under the influence of artificial fertilization, the input and output of phosphorus in Taihu Farm on the Taihu Port route are relatively large, leading to that the content of TP, IP and Fe-Al combined phosphorus in the sediments of Taihu Port is higher than that in other regions.

Table.4: The relationship between phosphorus forms and phosphorus adsorption in sediments

\begin{tabular}{|l|c|c|c|c|c|}
\hline Sampling point & $\mathbf{T P}(\mathbf{m g} / \mathbf{k g})$ & $\mathbf{I P}(\mathbf{m g} / \mathbf{k g})$ & $\mathbf{E x}-\mathbf{P}(\mathbf{m g} / \mathbf{k g})$ & $\mathbf{N a O H}-\mathbf{P}(\mathbf{m g} / \mathbf{k g})$ & HCl-P(mg/kg) \\
\hline Dredging point & 374.6 & 291.2 & 83.4 & 26.03 & 265.17 \\
\hline
\end{tabular}




\begin{tabular}{|l|c|c|c|c|c|}
\hline Wetland & 481.3 & 378.1 & 103.2 & 35.36 & 342.74 \\
\hline Riverside & 553.6 & 469.4 & 84.2 & 55.75 & 413.65 \\
\hline Taihu Farm & 376.63 & 304.23 & 72.4 & 46.21 & 258.02 \\
\hline Taihu Port & 654.8 & 530 & 124.8 & 304.38 & 225.62 \\
\hline $\mathbf{r}^{2}$ & $0.853 *$ & 0.637 & $0.971 * *$ & 0.534 & 0.528 \\
\hline
\end{tabular}

TP is total phosphorus; IP is inorganic phosphorus; NaOH-P is iron-aluminum-bound phosphorus; Ex-P is exchangeable phosphorus, HCl-P is calcium-bound phosphorus; * Significantly correlated at 0.05 level (both sides). ** Significantly correlated on the .01 level (both sides).

\subsection{The effect of coexisting heavy metal ions on $P$ adsorption-release}

Related studies have shown that ${ }^{[16 \sim 19]}$, the adsorption and release of phosphorus by sediments are affected by the types of heavy metal ions, the valence state of heavy metal ions, and the concentration of heavy metal ions. Deng Tiantian et al ${ }^{[20]}$ studied the influence of heavy metal pollution on soil adsorption of phosphorus under the influence of different external factors. The results showed that heavy metals had a certain inhibitory effect on soil adsorption of phosphorus, and the degree of inhibition was: $\mathrm{Cd}>\mathrm{As}>\mathrm{Cu}>\mathrm{Pb}$; Researches by Ge Chengfeng et al. ${ }^{[21]}$ showed that under the coexistence system of $\mathrm{Cu}^{2+}, \mathrm{Cu}^{2+}$ and $\mathrm{PO}_{4}^{-}$, heavy metals and phosphorus phases can mutually promote adsorption, thereby inhibiting desorption. The addition of $\mathrm{Cu}^{2+}$ and $\mathrm{Cd}^{2+}$ increases the adsorption rate and amount of $\mathrm{PO}^{-}$on the sediment. In this study, by formulating the mixed solution of high- and low- concentrations of heavy metal ions, the adsorption of phosphorus at two concentrations was investigated respectively.

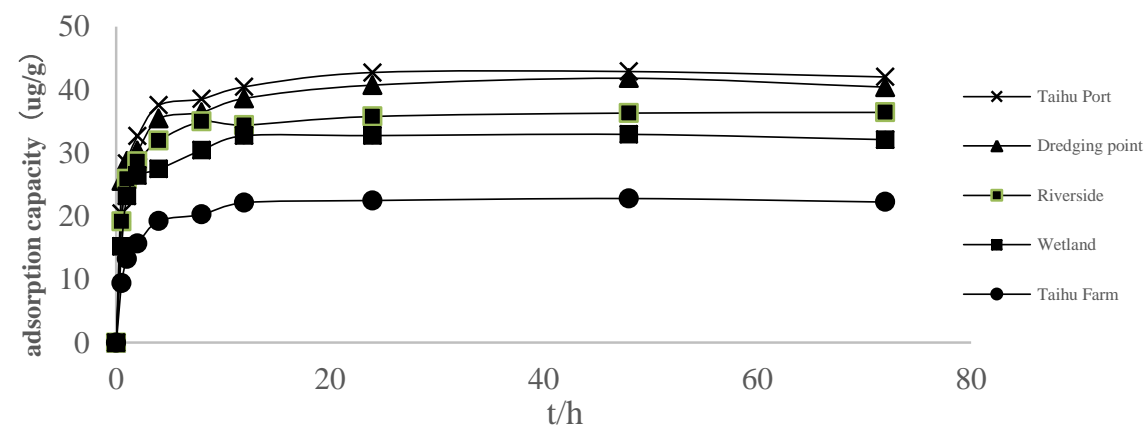

Figure.3 The effect of low-concentration heavy metal ions on the adsorption of phosphorus in sediments

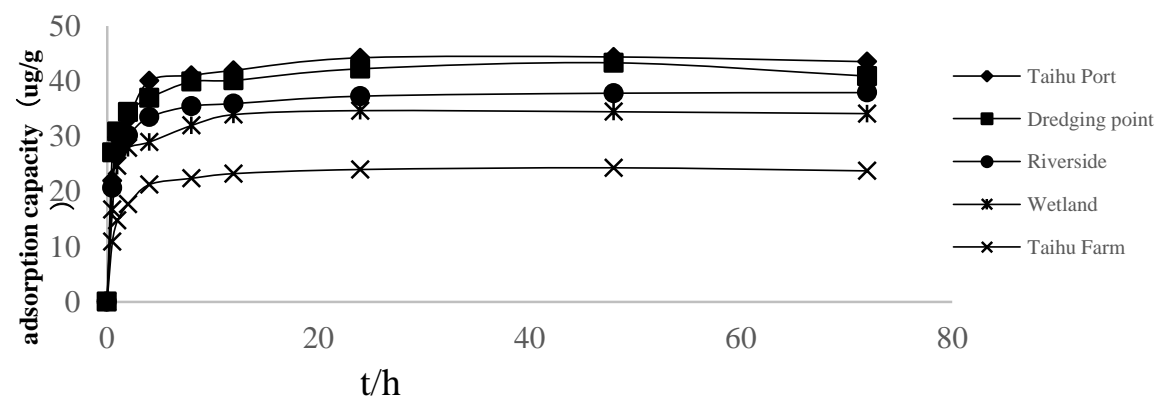

Figure.4 The effect of high-concentration heavy metal ions on the adsorption of phosphorus on sediments

It can be seen from Figures 3 and 4 that the addition of heavy metals in the system increased the adsorption rate of phosphorus in the sediment and reduced the adsorption equilibrium time. However, the adsorption amount was reduced. The equilibrium was basically reached in about 15 hours, and the adsorption kinetics of phosphorus in sediments showed a trend of "fast first and then slow". After adding heavy metals, it 
exhibited rapid adsorption at $0 \sim 2 \mathrm{~h}$. Heavy metals and phosphate ions competed for non-specific site adsorption, mainly physical adsorption, and phosphate ions coordinated with hydroxyl groups in the system; In $2 \mathrm{~h} \sim 8 \mathrm{~h}$, it exhibited slow adsorption. With the adsorption of phosphorus by sediments, the corresponding adsorption points became fewer and fewer. At the same time, the negative charge of the phosphate ions adsorbed on the surface of the sediment and the negative charge of the phosphate ions in the solution produced homosexual charge repulsion, inhibiting the adsorption rate of the phosphate ions, therefore the adsorption rate and the adsorption amount significantly reduced. There is a competitive adsorption relationship between heavy metals and phosphorus in the sediment, and as the amount of mixed heavy metal ion solution added increases, the more intense the competitive adsorption with phosphate and the lower the adsorption of phosphate ion in the sediment will be ${ }^{[22]}$.

\subsection{The influence of disturbance on phosphorus adsorption-release}

The results of the adsorption-release of phosphorus in the sediment are shown in the figure below. Studies have shown that ${ }^{[23 \sim 24]}$ as the intensity of the disturbance increases, the amount of phosphorus adsorption and release increases. The disturbance increases the contact area and the probability of contact between the sediment and $\mathrm{PO}_{4}^{-}$, therefore, the adsorption of phosphate and sediment will increase; at the same time, the disturbance also makes the phosphate ion adsorbed on the surface of the sediment easier to detach. However, the detached phosphate ion is mostly physically adsorbed on the surface of the sediment. Oscillation frequency increased from $0 \mathrm{rmp}, 75 \mathrm{rmp}$, to $150 \mathrm{rmp}$, the release rate of each sampling point increased from $16.7 \% \sim 21 \%$ to about $37.2 \% \sim 40.8 \%$, and the adsorption rate increased from $8.6 \% \sim 12.7 \%$ to $17.3 \% \sim$ $22.6 \%$. It can be seen that the disturbance has a greater effect on the adsorption and release of phosphorus in the sediment. However, compared to adsorption, it has a greater impact on the amount of release.

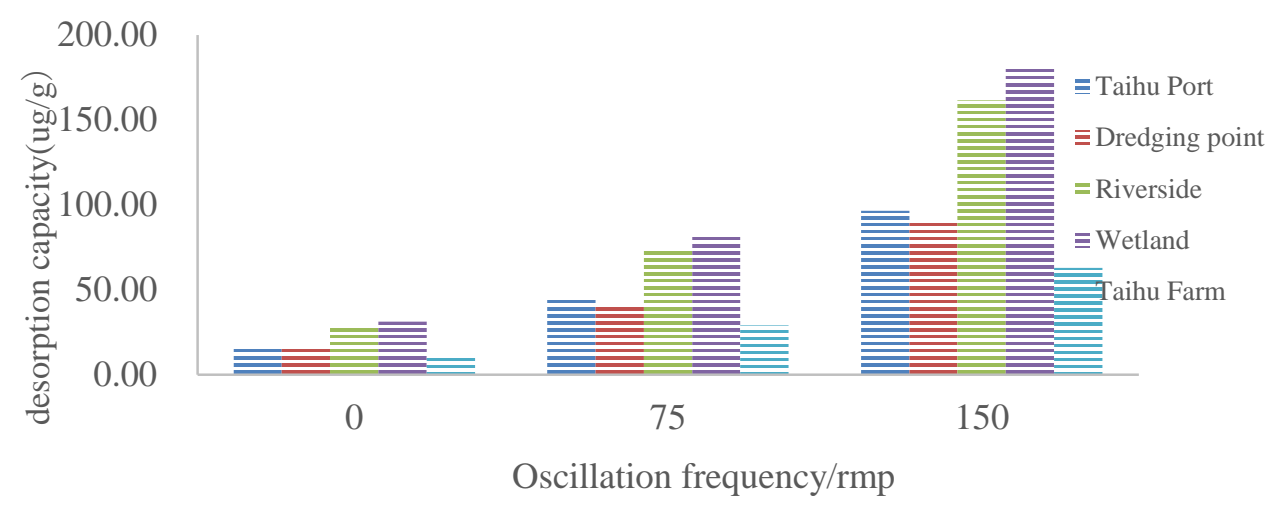

Fig .5 Desorption of phosphorus by sediment at different oscillation frequencies

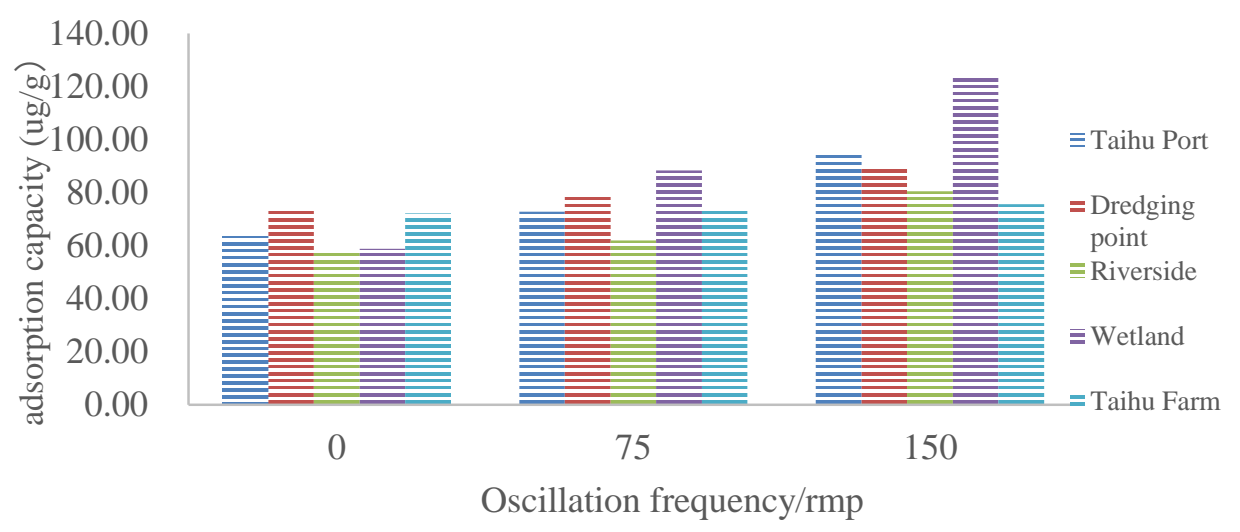

Fig .6 P adsorption capacity of sediment at different oscillation frequencies 


\section{Analysis of various influencing factors through principal component analysis}

Principal component analysis can transform multi-index problems into smaller new index problems. The converted index is the main component of the original index, which is a linear combination of the original indexes, and these new indexes, not relating to each other, can comprehensively reflect the information of the original multi-index ${ }^{[2526]}$. In this experiment, the adsorption and release of phosphorus under the five factors including temperature, disturbance, heavy metal content, particle size and organic matter content $\left(\mathrm{x}_{1} \sim \mathrm{X}_{5}\right)$ were used as the original indicators, and the following analysis was performed with SPSS analysis software.

Table 5: Correlation analysis matrix

\begin{tabular}{|c|c|c|c|c|c|}
\hline Factor & $\mathbf{x}_{\mathbf{1}}$ & $\mathbf{x}_{\mathbf{2}}$ & $\mathbf{x}_{\mathbf{3}}$ & $\mathbf{x}_{\mathbf{4}}$ & $\mathbf{x}_{\mathbf{5}}$ \\
\hline $\mathrm{x}_{1}$ & 1 & 0.912 & 0.202 & 0.912 & 0.815 \\
\hline $\mathrm{x}_{2}$ & 0.912 & 1 & 0.145 & 1 & 0.572 \\
\hline $\mathrm{x}_{3}$ & 0.202 & 0.145 & 1 & 0.145 & 0.22 \\
\hline $\mathrm{x}_{4}$ & 0.912 & 1 & 0.145 & 1 & 0.572 \\
\hline $\mathrm{x}_{5}$ & 0.815 & 0.572 & 0.22 & 0.572 & 1 \\
\hline
\end{tabular}

Table6: Total variance explained

\begin{tabular}{|c|c|c|c|c|c|c|}
\hline \multirow{2}{*}{ Component } & & $\begin{array}{l}\text { Initial } \\
\text { eigenvalue }\end{array}$ & & & $\begin{array}{l}\text { Extract square sum and } \\
\text { load }\end{array}$ & \\
\hline & \begin{tabular}{|l|} 
Total \\
\end{tabular} & $\%$ of variance & $\begin{array}{l}\text { Cumulative } \\
\%\end{array}$ & Tota & $\%$ of variance & $\begin{array}{l}\text { Cumulative } \\
\%\end{array}$ \\
\hline $\mathrm{x}_{1}$ & 3.464 & 69.279 & 69.279 & 3.464 & 69.279 & 69.279 \\
\hline $\mathrm{x}_{2}$ & 0.969 & 19.375 & 88.654 & & & \\
\hline $\mathrm{x}_{3}$ & 0.539 & 10.779 & 99.433 & & & \\
\hline $\mathrm{x}_{4}$ & 0.028 & 0.567 & 100 & & & \\
\hline $\mathrm{X}_{5}$ & $\begin{array}{c}2.72 \mathrm{E}- \\
16 \\
2.72 \mathrm{E}- \\
16 \\
2.72 \mathrm{E}- \\
16\end{array}$ & $\begin{array}{l}5.43 \mathrm{E}-15 \\
5.43 \mathrm{E}-15 \\
5.43 \mathrm{E}-15\end{array}$ & 100 & & & \\
\hline
\end{tabular}

Through the data analysis of the total variance explained in the component analysis, it can be seen that the cumulative contribution rate of the two components of temperature and disturbance have reached $88.65 \%$ [27], which is greater than $85 \%$, therefore these two components are selected. The output matrix of the two principal components was extracted, and the result is as follows:

Table 7: Principal component matrix

\begin{tabular}{|c|c|c|}
\hline & $\mathbf{y}_{1}$ & $\mathbf{y}_{2}$ \\
\hline $\mathrm{x}_{1}$ & 0.985 & 0.932 \\
\hline $\mathrm{x}_{24}$ & 0.910 & 0.962 \\
\hline $\mathrm{x}_{3}$ & 0.263 & 0.138 \\
\hline $\mathrm{x}_{4}$ & 0.839 & 0.914 \\
\hline $\mathrm{x}_{5}$ & 0.79 & 0.731 \\
\hline
\end{tabular}

Table 8: Principal component coefficient table

\begin{tabular}{|l|l}
\hline $\mathbf{y}_{1}$ & $\mathbf{y}_{2}$
\end{tabular}




\begin{tabular}{|c|c|c|}
\hline $\mathrm{x}_{1}$ & 0.284 & 0.253 \\
\hline $\mathrm{x}_{2}$ & 0.259 & 0.272 \\
\hline $\mathrm{x}_{3}$ & 0.076 & 0.047 \\
\hline $\mathrm{x}_{4}$ & 0.247 & 0.201 \\
\hline $\mathrm{x}_{5}$ & 0.228 & 0.195 \\
\hline
\end{tabular}

The linear combination of the two principal components in the table is:

$$
\begin{aligned}
& \mathrm{y}_{1}=0.284 \mathrm{x}_{1}+0.276 \mathrm{x}_{2}+0.076 \mathrm{x}_{3}+0.274 \mathrm{x}_{4}+0.228 \mathrm{x}_{5} \\
& \mathrm{y}_{2}=0.263 \mathrm{x}_{1}+0.252 \mathrm{x}_{2}+0.047 \mathrm{x}_{3}+0.232 \mathrm{x}_{4}+0.195 \mathrm{x}_{5} ;
\end{aligned}
$$

Therein $\mathrm{x}_{1} \sim \mathrm{x}_{5}$ represent the variables after the original variables are normalized, and the significance of the principal component is determined by one or several indicators with the largest weight in the linear combination. When the weight coefficient is relatively large, the comprehensive factor $y$ is a comprehensive reflection of the influencing factors, which indicates the amount of phosphorus adsorbed by the sediment under the influence of various factors (temperature, disturbance, heavy metal ion content, particle size and organic matter content). It can be seen from the two linear combinations that the four indexes y1 including $\mathrm{x}_{1}, \mathrm{x}_{2}, \mathrm{x}_{4}$, and $\mathrm{x}_{5}$ in the comprehensive factor account for a considerable proportion, and are greatly affected by temperature, disturbance, particle size and organic matter content, further showing that these four factors are indispensable influencing factors in the process of adsorption and release of phosphorus in sediments; However, in the linear combination of the comprehensive factor $\mathrm{y}_{2}, \mathrm{x}_{1}$ and $\mathrm{x}_{2}$ account for the main proportion, that is, the release of phosphorus is mainly affected by temperature and disturbance.

After vectoring the principal components, it was:

\section{Table9: Principal component vector table}

\begin{tabular}{|c|c|}
\hline $\mathbf{y 1}$ & $\mathbf{y 2}$ \\
\hline 0.518 & 0.439 \\
\hline-0.330 & -0.307 \\
\hline-1.069 & -0.945 \\
\hline 1.246 & 1.122 \\
\hline-0.171 & -0.309 \\
\hline
\end{tabular}

Comprehensive principal component value $\mathrm{Y}=0.70711_{\mathrm{y} 1}+0.08032_{\mathrm{y} 2}$, the sorted result is:

Table10: Comprehensive principal component analysis results

\begin{tabular}{|c|c|}
\hline $\mathbf{Y}$ & Sort \\
\hline 0.902 & 1 \\
\hline-0.258 & 4 \\
\hline-0.832 & 5 \\
\hline 0.471 & 2 \\
\hline-0.145 & 3 \\
\hline
\end{tabular}

\subsection{Evaluation of the analysis results}

Through the principal component analysis method, the amount of phosphorus adsorbed by different types of sediments and the factors affecting the adsorption were calculated and analyzed. From the analysis results, it can be seen that the influences of the external environment on the sediments of different types and sources are ranked as follows: temperature> disturbance> organic matter content $>$ heavy metal ion influence> 
sediment size. The contribution to the first principal component of phosphorus adsorption in sediments is temperature. The integrated principal component analysis value is 0.902 . As the temperature rises, the adsorption and release of phosphorus show an increasing trend. In the rivers and lakes treated, phosphorus can be treated in a controlled season; followed by disturbance factors, the comprehensive principal component value of which is 0.407 . In the process of treating phosphorus in the sediment, the release of phosphorus was reduced by reducing the disturbance to the sediment. The total principal components of the third, fourth, and fifth contribution components are $-0.145,-0.258$, and -0.832 . Under the premise of controlling external input, the phosphorus content in the water was reduced by purifying the water quality. The above analysis shows that different influencing factors have different effects on the adsorption and release of phosphorus in sediments. However, in general, they will jointly affect the adsorption performance.

\section{Conclusion}

1. Within $0 \sim 0.5 \mathrm{~h}$, the release rate of the sediment to phosphorus is the fastest and the release amount is the largest. As the release progresses, Within $0.5 \mathrm{~h} \sim 8 \mathrm{~h}$, the rate gradually decreases and reach the release equilibrium point at $24 \mathrm{~h}$.

2. The results of adsorption kinetics show that the sediments at the five sampling points have different adsorption effects on phosphorus and different adsorption capacities. About $0 \sim 1 \mathrm{~h}$, the adsorption capacity and adsorption rate were the largest. The adsorption saturation equilibrium was concentrated at $10 \mathrm{~h}$ and at about $24 \mathrm{~h}$, the adsorption saturation state was basically achieved.

3. The phosphorus adsorption behavior of the sediments at the five sampling points is in good agreement with the Freundlich and Langmuir models. The maximum adsorption amount of phosphorus in sediments from the five sampling points Qmax is between $0.61 \mathrm{mg} \cdot \mathrm{g}^{-1} \sim 0.89 \mathrm{mg} \cdot \mathrm{g}^{-1}$. The amount of phosphorus adsorbed by sediments had a significant positive correlation with Ex-P, TOC, CEC and TP.

4. The principal component analysis method was used to analyze the influence on the adsorption and release of phosphorus in the sediment by the external environment temperature, disturbance, heavy metal content, particle size and organic matter. The experimental results show that temperature changes have the greatest effect on the adsorption and release of sediments, followed by the degree of disturbance, organic matter content, the presence of heavy metal ions, and sediment particle size. The results of this study can be used as a reference for river and lake sediment management.

\section{References}

[1.] Sakadevan K, Bavor H J. Phosphate Adsorption Characteristics of Soils, Slags and Zeolite to be Used as Substrates in Constructed Wetland Systems [J]. Water Research, 1998, 32 (2): 393-399.

[2.] Dong Xiaole, Yu Shihua, Lin Cuihua, etc. The Effect of Coexisting Anions on the Adsorption of Phosphate by Niobium Hydroxide [J]. Science Technology in Chemical Industry (1): 34-37.

[3.] $\mathrm{Hu}$ Hongqing, Li Yan, He Jizheng. Studies on the Interaction between Organic Acids and Phosphorus in the Soil [J]. Chinese Journal of Soil Science (2): 127-134.

[4.] Pang Yan. Studies on Phosphorus Forms and Phosphorus Adsorption Characteristics of Sediments in the Five Great Lakes. Beijing: Master's Thesis of Chinese Academy of Environmental Sciences, 2004

[5.] Wang Qiaohuan, Ren Yufen, Meng Ling, et al. Simultaneous Determination of Total nNitrogen and Organic Carbon in soil by element analyzer [J]. Chinese Journal of Analysis Laboratory, 2013 (10): 46-50.

[6.] Xu Xiangying. Studies on the Interaction of Cadmium and Phosphorus in Soil-plant System [D]. Southwest Agricultural University, 2001.

[7.] Zhuge Xiangzhen, Bi Chunjuan, etc. Adsorption of Phosphorus of Soil and Sediments around Dishui Lake in Shanghai [J]. Acta Scientiae Circumstantiae, 2014, 35 (4): 1531-1539.

[8.] Harmonized protocol and certified reference material for the determination of extractable contents of phosphorus in freshwater sediments - A synthesis of recent works[J] . V. Ruban,J. F. LópezSánchez,P. Pardo,G. Rauret,H. Muntau,Ph. Quevauviller.Fresenius' Journal of Analytical Chemistry.2001 (2-3)

[9.] Liu Yi. Effects of Oxides in Soil / Sediment on the Behavior of Phosphorus and Heavy Metals [J]. Journal of Sichuan Forestry Science and Technology, 2014, 35 (3): 13-20. 
[10.] Wenqiang Zhang,Baoqing Shan,Jie. Characteristics, distribution and ecological risk assessment of phosphorus in surface sediments from different ecosystems in Eastern China: A 31 P-nuclear magnetic resonance study[J].Ecological Engineering .2014

[11.] Bin Zhang,Fang Fang,Jinsong Guo.Phosphorus fractions and phosphate sorption-release characteristics relevant to the soil composition of water-level-fluctuating zone of Three Gorges Reservoir[J].Ecological Engineering.2011.

[12.] Ji-Hyock Yoo,Hee-Myong Ro,Woo-Jung Choi.Phosphorus adsorption and removal by sediments of a constructed marsh in Korea[J]. Ecological Engineering.2005 (2) .

[13.] Li Beigang, Gao Na, Ma Qin. The Phosphate Adsorption / Release Behavior of Sediments in the Upper and Middle Reaches of the Yellow River [J]. Journal of Ecology and Rural Environment 2010, 26 (4): 356-360.

[14.] Xiong Yunling, Guo Zhiwen, Liang Yuxiang. Researches on the Effect of Competitive Adsorption on the Migration of Phosphorus in Soil [J]. Modern Agricultural Science and Technology, 000 (12): 209-212.

[15.] Liu Haiting, Zhao Yang, Yu Ruilian, et al. Adsorption and Desorption Characteristics of Soil phosphorus Under Different Utilization Methods in Quanzhou [J]. Chinese Journal of Ecology, 2011, 30 (06): 1114-1118.

[16.] Li Dapeng, Huang Yong.The Influences of Disturbance Intensity on Phosphorus Release and Morphological Transformation in the Sediments of Taihu Lake [J]. Environmental Science, 033 (8): 2614-2620.

[17.] Shengrui Wang,Xiangcan Jin,Qingyun Bu,Xiaoning Zhou,Fengchang Wu.Effects of particle size, organic matter and ionic strength on the phosphate sorption in different trophic lake sediments[J] . Journal of Hazardous Materials.2005 (2)

[18.] Gao Li, Shi Yanxi, Sun Weiming, et al. Analysis of Phosphorus Adsorption Characteristics and Influencing Factors in the Sediments of Rongcheng Swan Lake Wetland[J]. Journal of Soil and Water Conservation, 2009 (05): 165-169 + 207.

[19.] Yu Jiazhen, Wang Xiaochang, Xue Tao, et al. The Adsorption and release characteristics and phosphorus forms of sediments in Hancheng Lake, Xi'an at different temperatures [J]. Chinese Journal of Environmental Engineering, 2016 (11): 6275-6282

[20.] Deng Tiantian, Duan Haixu, Liu Bibo, et al. The Effects of Four Typical Heavy Metal Pollution on the Adsorption of Phosphorus in Soil[J]. Chinese Journal of Soil Science, 2019 (2): 463-473.

[21.] Ge Chengfeng. Studies on Adsorption / Desorption Behavior of Copper, Cadmium and Phosphorus in Marine Sediments [D]. Qingdao: Ocean University of China, 2012.

[22.] Huang Shuhui, Zeng Guanghui, Huang Hong. Studies on Phosphorus Adsorption and Desorption in Wetland Sediments[J]. Journal of Soil and Water Conservation, 2008 (02): 189-192.

[23.] Xia Hanping, Gao Ziqin. The Mechanism of Competitive Adsorption and Desorption of Phosphate in Soil[J]. Chinese Journal of Applied Ecology, 1993 (1).

[24.] Hu Hongqing, He Jizheng, Li Xueyuan.The Effects of the Coexistence of Various Organic Acids on Phosphorus Adsorption by Variable Charge Soils[J]. Journal of Plant Nutrition and Fertilizer, 1999 (02): 27-33.

[25.] Wang Shuhang, Zhang Bo, Jiang Xia, et al. Analysis of Phosphorus Fractions in Sediments by Sequential Extraction[J]. Environmental Science Research, 028 (9): 1382-1388.

[26.] Li Yu, Yu Zhiming, Song Xiuxian. Using Principal Component Analysis (PCA) to Evaluate the Sources of Heavy Metal Pollution in Marine Sediments [J]. Environmental Science (1): 139-143.

[27.] Liao Chunling. Relationship between Nitrogen and Phosphorus Occurrence Modes and the Adsorption Characteristics of Sediments of Different Granulometric Classes in Yao Lake and the Nutritional Status of Water Bodies[D]. East China Jiaotong University. 